\title{
Why Family Memories and Stories Matter
}

\section{ANNA GREEN}

\begin{abstract}
Comparatively little is known about the content and form of family memory among Pākehā (New Zealanders of European descent) in contrast to the centrality of whakapapa/genealogy in mātauranga Māori. To address this lacuna, the Marsden-funded research project "The Missing Link" recorded oral history interviews with sixty multigenerational families descended from European migrants who arrived in New Zealand before 1914. We asked our participants what they knew about their family past, the stories that had been passed down, and why particular ancestors interested them. The analysis of these oral history interviews is in progress. This article focuses on the decision to employ a mixed methods research methodology, including an analytical conceptual framework drawn from memory studies, and draws some preliminary conclusions regarding the Pākehā family as a mnemonic community.
\end{abstract}

\section{Introduction}

Family history is currently undergoing something of a renaissance through a new research engagement between historians and genealogists, with the goal of constructing a much more fine-grained understanding of the family in the past. ${ }^{1}$ Family memories and oral histories, however, tend to be marginalised in this collaboration. At the "Related Histories: Studying the Family" Canberra conference in late 2017, for example, genealogists in the audience, and some historians and quantitative sociologists among the presenters, were dismissive of family memory. Perceived as unreliable, partial, and self-aggrandising, commentators questioned whether memory and stories are worthwhile sources for family historians. Similar comments have been made in Pākehā [New Zealand European] genealogical circles, where archival documentation reigns supreme. This is especially curious given that pre-1966 New Zealand census returns were almost entirely destroyed (only aggregated anonymous tables survive), and other popular public records such as newspapers are rarely illuminating about the interior world of the family. ${ }^{2}$

The rejection of the significance of family memories is not, of course, shared by Māori historians, for whom iwi and hapū whakapapa and oral histories are the foundation for personal and collective identities. ${ }^{3}$ Nor is it shared by contemporary international scholars working, for example, on migrant family histories or the intergenerational transmission of trauma and violent pasts. ${ }^{4}$ Furthermore, the multidisciplinary, international scholarly turn to the study of memory and remembering over the past forty years or so, by historians, sociologists, anthropologists, psychologists, and literary scholars, has generated a rich body of analytical and interpretative approaches. These clarify the processes of remembering, identify oral history's unique characteristics and strengths, and suggest the ways in which memory matters in the present at all levels of society, from the individual to the nation state.

One of the most significant approaches from this interdisciplinary scholarship, for the purposes of this article, concerns the reformulation of notions of the "self" into narratives of self-identity. In other words, building on the research of the American psychologist Jerome Bruner in particular, self-identities are narratively constructed drawing upon experiences, memories and cultural models in what he describes as "an interpretative feat" in search of meaning. ${ }^{5}$ Narrative

Journal of New Zealand Studies NS29 (2019), 3-19 https://doi.org/10.26686/jnzs.v0iNS29.6257 
is at the core of this conceptualisation of self-identity, and Bruner further argues that "we know that narrative in all its forms is a dialectic between what was expected and what came to pass. For there to be a story, something unforeseen must happen. Story is enormously sensitive to whatever challenges our conception of the canonical." Later in the same paragraph, Bruner also notes that "We more often tell stories to forewarn than to instruct."

In this article I want build upon Bruner's argument in the context of a New Zealand oral history project on family memory entitled "The Missing Link." Very little is known about the content and form of family memory among Pākehā (New Zealanders of European descent), and this research set out to address that lacuna. Do New Zealanders of European descent share family oral histories about the past? If they do, what kinds of stories do they pass down the generations, and how are these stories, or the findings of conventional genealogical research, interpreted by descendants in the present? The analysis of the oral histories recorded for this research is still in progress, and here I will draw upon a few specific examples to illustrate one emerging theme: gender. But just as the scope and findings of archival historical research rest upon the approach and methodology of the researcher, so too does oral history research into family memory. I will begin, therefore, with the research methodology and conceptual frameworks employed in this New Zealand study into European settler family memory.

\section{"The Missing Link"}

In late 2015, the Social Sciences Panel of the Marsden Fund awarded "The Missing Link" research project a grant of just over half a million dollars to investigate the memories and transmission of family stories among European settler descendants. The project proposed to record oral history interviews with 50 multigenerational families descended from European settlers who arrived in New Zealand before $1914 .{ }^{7}$ One of the key initial questions, of course, was how to find such a large national oral history cohort. As Carla Pascoe Leahy has argued, the issue of participant selection and sampling is an especially critical decision for the oral historian but rarely receives the attention it deserves. ${ }^{8}$ It may be valuable, therefore, to compare the approach in "The Missing Link" with a recent, large collaborative oral history research project in Australia. The "Australian Generations" project, a partnership between five university historians (and other oral history interviewers), the National Library of Australia and the Australian Broadcasting Corporation (ABC) Radio National, and with funding of around one million Australian dollars, recorded "fifty interviews with people born in each decade from the 1930s to the 1980s." The researchers sought to "explore social and cultural change across time and compare the experience of different birth cohorts . . and interrogate assumptions implicit within generational labels such as 'baby boomer,' 'Gen $\mathrm{X}^{\text {' }}$ and 'Gen Y."' Researchers were able to advertise for interviewees through $\mathrm{ABC}$ national and regional programmes, as well as social media, community networks and word of mouth. Just under half of the 684 volunteers were ultimately selected for inclusion, and the researchers argue that they were able to achieve a good spread in the categories such as age, gender (just under half were men), and region. The Australians acknowledged, however, that "social class" was the most difficult attribute to judge among the cohort, and explained that educational level was used as an approximate indicator. ${ }^{10}$ Whilst not a representative sample, because it was based upon people volunteering to be interviewed, the aim of the project was to create an archive "large enough to support suggestive generalisations." 11

How did the approach in "The Missing Link" differ from that of "Australian Generations"? A representative sample was not a feasible goal for this research either, given that it is impossible to establish how many or which New Zealanders fitted the research parameters. But the project 
aimed to explore the spectrum of family approaches to the past and shared the goal of being able to reach "suggestive generalisations," in this case about the transmission of family memory and knowledge among the descendants of nineteenth-century European migrants in New Zealand. As the project lead, and aware of the widespread and popular practice of genealogical research, I was concerned that families would inevitably nominate, if she or he were still alive, the family genealogist. The primary concern, therefore, was to reach those who might otherwise not respond to a general call through public media to participate in an oral history project of this nature. It was essential to extend the interviews well beyond active genealogists if it were to be possible to reach suggestive generalisations for this group as a whole.

Since the budget allowed us to record a large national interview cohort of families from all regions of New Zealand, it was therefore decided to contact potential interviewees directly through a random sample of the national General Electoral rolls. Letters were posted to 3,000 individuals over the age of 30 years all over New Zealand. The decision to select those over 30 years of age was made to maximise a successful response: an earlier pilot project in the UK had demonstrated that little response was likely from recipients in their twenties. ${ }^{12}$ Those receiving the letter were asked if they had a European forebear who migrated to New Zealand before the onset of the First World War. Many recipients, such as those whose migrant families came from places other than Europe in the past or present, would not of course fit this selection criteria. And following high inward migration during the past decades, a quarter of the population were not born in New Zealand at the time of the 2013 census, with that figure increasing in the most recent 2018 census. ${ }^{13}$

Second, the letter asked if one member from each adult generation of the recipient's family would be willing to record an interview about their knowledge and memories of the family past. The definition of "family" and who would be asked to contribute, therefore, was determined by the recipient of the letter. Over the first week or two the answers initially trickled in, then became a flood as the recipients discussed with family members from older or younger generations whether they would also be willing to contribute to the research. Attempts to redirect the invitation to another family member, perceived to be more knowledgeable, were resisted. I am deeply indebted to the final group of respondents for their contribution and assistance: their support made it possible to fulfil the intergenerational dimension of this research.

Much to our regret, due to financial constraints, we were unable to include all the families who volunteered, but were ultimately able to expand to 60 multigenerational families and to record 146 individual oral history interviews. The first 50 families were accepted for the research project on a first come, first served basis; the final ten were selected to increase the number of participants with migrant forebears who arrived in the $1870 \mathrm{~s}$ - a decade underrepresented in the initial group - and to maximise three-generational participation. The final generational family profile is as follows: 


\section{FAMILIES BY NUMBER OF GENERATIONS}

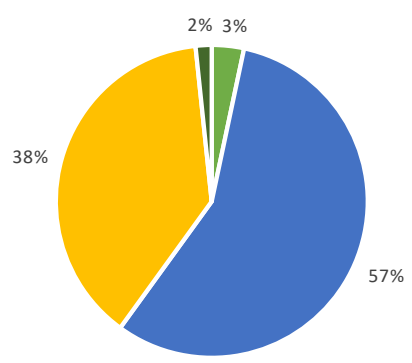

$=1 \cdot 2=3 \cdot 4$

Figure 1. Generational Family Profile.

Not all families responding to our letter had three adult living generations, but the predominance of two-generational families was also partly a consequence of an apparent reluctance to participate on the part of the youngest adult generation. This corresponds with the earlier pilot project on family memory in the UK, and reflects the forward-looking perspective of those in their twenties compared with the turn to the remembered past on the part of older generations. ${ }^{14}$ Finally, I am very grateful that a small group of families with both European and Māori ancestry responded to the letters and participated in the project, and their oral histories have added an invaluable dimension to the research.

Did the random sample achieve the objectives outlined a little earlier? The use of mixed methods, utilising both quantitative and qualitative methods, remains an unusual combination in large oral history research projects where, as in the "Australian Generations" project, snowballing, advertising for volunteers, and selection are more common. ${ }^{15}$ But there were very good reasons for finding "The Missing Link" oral history sample this way. First of all, by this initial random throw of the net it was hoped to avoid, as discussed earlier, reaching only those with well-established genealogical research interests. In terms of avoiding only practicing genealogists it was successful. While many of the families possessed some form of written, self-published account of the family past, these had usually been compiled by somebody else in the wider family, often from an earlier generation, and not by the family members who were interviewed. Interviewees would occasionally pull the book off the bookshelf to check their recall of names, dates and places and we were able to learn which parts of this genealogical research were of most interest to them and how they wove selected parts of this knowledge into the longer narrative trajectory about the family. In addition, we were also able to record stories that had been transmitted orally across the generations, most of which were not included in the written publications. Finally, the comments of some interviewees indicated that the direct personal invitation to participate encouraged them to come forward even though they did not feel confident that they knew enough about the family past, and these participants are unlikely to have responded to a general call for volunteers.

The random sample has been analysed for geographic spread, occupation and gender. In the tables and analyses that follow, the sample is broken down into three categories: Recipients who received the initial letter, Respondents who replied to the letter, and Participants who were interviewed for the project. In terms of regional participation, the random sample was 
successful in ensuring that interviewees were drawn from all over the north and south islands. Figure 2 below breaks down the participants into regions and the urban/rural divide:

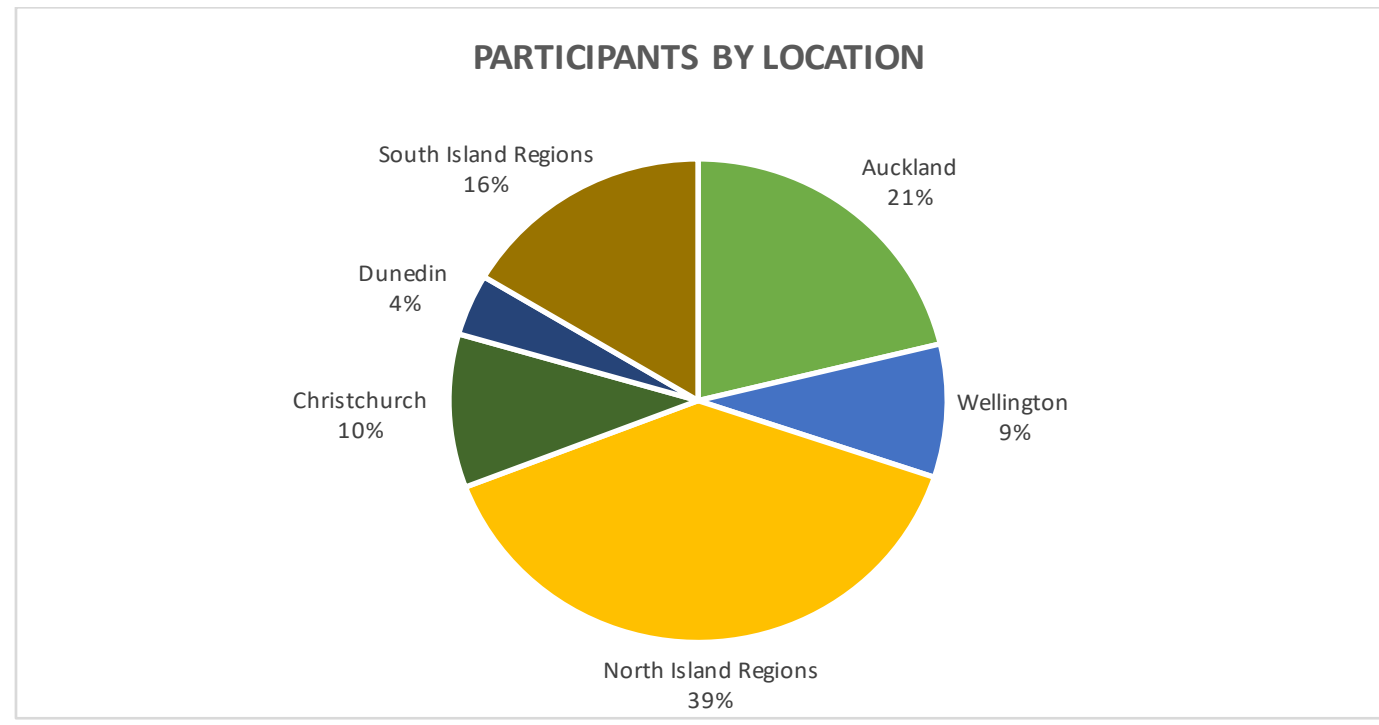

Figure 2. Location of Participants.

This geographic spread is important for the following reason. It was important not to predetermine the significance of place by focusing only upon those sites with well-established links to particular waves of nineteenth-century European migration and where the settlement's origins are still celebrated, such as the Scots of Waipū. Attachments to place remain powerful for some of the participants, particularly those who continue to live in the same area or on land inherited from the original European migrant, or for those with combined Māori ancestry and connections to specific iwi. But not all interviewees lived in the same place or even region where their earlier ancestors had settled and their attachments to place were more variable and recent in origin.

Turning to the socioeconomic profile of the project participants, rather than take educational level to signify class, as in the "Australian Generations" project, it was decided to code all Recipients and Participants on the basis of the 2013 Australian and New Zealand Standard Classification of Occupations (ANZSCO) and to compare these figures with those from the 2013 census over the age of 15 years: 


\begin{tabular}{|c|c|c|c|c|}
\hline \multirow[b]{2}{*}{ Occupation } & \multicolumn{4}{|c|}{ Comparison: Occupation } \\
\hline & NZ Census 2013 & \begin{tabular}{|c|}
$\begin{array}{c}\text { NZ Census } 2013 \text { adjusted to } \\
\text { include those not in labour force }\end{array}$ \\
\end{tabular} & $\begin{array}{c}3000 \text { recipients classified } \\
\text { in General Electoral Roll } \\
\end{array}$ & \begin{tabular}{|c|}
146 participants classified \\
in General Electoral Roll
\end{tabular} \\
\hline Managers & $18 \%$ & $12 \%$ & $12 \%$ & $6 \%$ \\
\hline Professionals & $21 \%$ & $14 \%$ & $19 \%$ & $32 \%$ \\
\hline nicians and Trade Workers & $11 \%$ & $8 \%$ & $8 \%$ & $2 \%$ \\
\hline \begin{tabular}{|l|} 
Community and Personal Service Workers \\
\end{tabular} & $9 \%$ & $6 \%$ & $4 \%$ & $3 \%$ \\
\hline Clerical and Administrative Workers & $11 \%$ & $8 \%$ & $7 \%$ & $5 \%$ \\
\hline Sales Workers & $9 \%$ & $6 \%$ & $4 \%$ & $1 \%$ \\
\hline Machinery Operators and Drivers & $5 \%$ & $3 \%$ & $4 \%$ & $1 \%$ \\
\hline \begin{tabular}{|l|} 
Labourers \\
\end{tabular} & $11 \%$ & $8 \%$ & $5 \%$ & $2 \%$ \\
\hline Response Unidentifiable & $2 \%$ & $1 \%$ & $3 \%$ & $3 \%$ \\
\hline Housewives, retired, students, etc. & $0 \%$ & $31 \%$ & $29 \%$ & $47 \%$ \\
\hline \begin{tabular}{|l|} 
Non-response \\
\end{tabular} & $3 \%$ & $2 \%$ & $5 \%$ & $0 \%$ \\
\hline & $100 \%$ & $100 \%$ & $100 \%$ & $100 \%$ \\
\hline
\end{tabular}

Table 1. Occupation of Participants.

Table 1 suggests interesting comparisons between the oral history cohort and the overall adult population census and electoral roll profiles. First, the largest category in all four columns is a combined group defined by being out of the labour force, including mothers at home, the retired, and students. It had been anticipated that at least a third of the participants would be retired, given the multigenerational nature of the project, and that some of the youngest generation might be in some form of tertiary or continuing education. The high rate of participation by these groups in the research may also reflect their availability to allocate several hours for an oral history interview, unlike those in paid employment for whom it was much more difficult.

Second, the participants cluster significantly in the professional category. There are a number of reasons for this. In terms of methodology, limiting the invitation letters to those 30 years of age and over inevitably had the effect of lifting the final cohort higher in the socioeconomic classifications. Families that fitted the research criteria have also lived in New Zealand for up to six generations and many have built economic and educational capital over that time. The higher participation rate in the category of professionals could also reflect the impact of a tertiary education leading to a more positive perception of research and publication.

But the gendered nature of the participant cohort is also very likely to be a critical factor in the socioeconomic profile. The most significant single dimension of the random sample was the predominance of women both as respondents to the initial letter and among the final group of participants. Two-thirds of the initial respondents were women, as were the family participants who recorded interviews: 


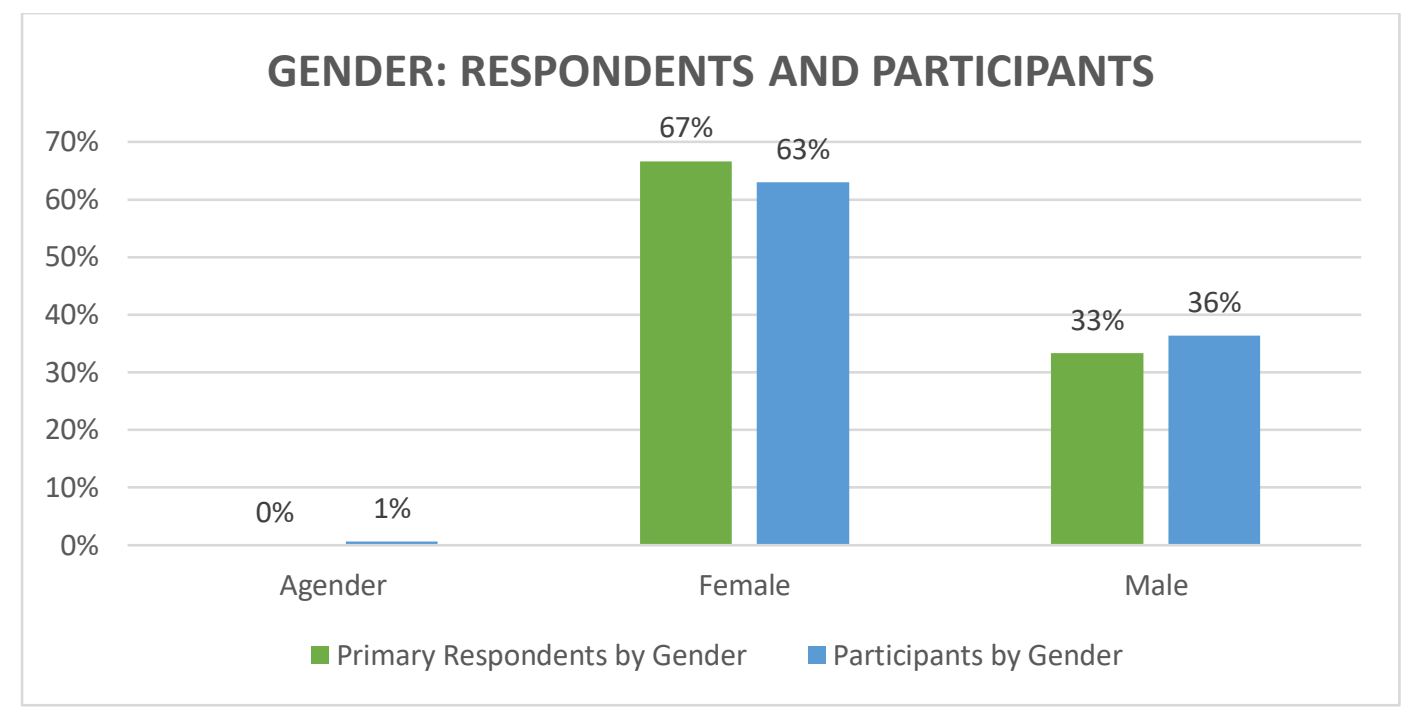

Figure 3. Gender of Respondents and Participants.

Men and women have very different occupational profiles in New Zealand. For example, women are much less likely than men to be employed in lower skilled manual jobs or the manual trades, or agriculture and fisheries, and more likely than men to work in professional occupations. In the latter they are concentrated primarily in nursing and teaching. ${ }^{16}$ This statistical profile was reflected in our female participants: of those working in professional occupations, 19 percent were nurses and 29 percent teachers, while others were employed in a wide range of fields ranging from engineering to veterinary science. Gender is, therefore, likely to have played a significant role in the socioeconomic profile of the oral history cohort outlined in Table 1.

The high number of women participating in the project was not entirely unexpected. American social and cultural psychologists argue that adult women express generativity, defined broadly as responsibility for and nurturing the next generation, in part through communicating family stories about the past. ${ }^{17}$ Through recording mealtimes, for example, the psychologist Robyn Fivush demonstrated the ways in which contemporary mothers pass on family memories and stories. ${ }^{18}$ And historians Roy Rosenzweig and David Thelen, in their groundbreaking survey exploring how Americans connect with the past, found that "many Americans see the job of maintaining a sense of continuity with the past broadly defined as part of 'women's work" within the family," though they suggested more research was needed. ${ }^{19} \mathrm{Had}$ we selected an equal number of men and women through a snowballing methodology we could have missed this supporting evidence regarding the gendered nature of family memory transmission.

Many women participating in the project explicitly identified the importance of the grandmother/mother/daughter relationship in sharing family stories. In the following family, as an example, interviews were recorded with a mother and daughter. Julien is a legal executive born in 1953 and Lucie, presently an at-home mother, was born in 1981. The family is descended from Swedish, Danish, English and Scots migrant forebears who originally migrated to New Zealand in the 1850s and 1870s. Julien began her account of the family as follows:

I'll start with my mother's side of the family first. I feel more connected to my mother's side because the information I have from that side of the family is more 
anecdotal. I think it's something to do with being female and women connecting with women and the social aspect, the women were the sort of glue that kept families together. Whereas on my father's side the information I've obtained is more factual [she points to a red book on the table compiled by a "distant cousin chap"]. ${ }^{20}$

Julien was particularly interested in the lives of her female forebears, and how they managed to hold families with young children together in the face of widowhood or family disaster. She told the story of her Swedish great grandmother Olivia who was widowed when young with nine children "and no benefits in those days." ${ }^{21}$ Olivia subsequently remarried twice more for, Julien suspects, economic survival. Another female forebear married a seaman who spent most of his life away from home and she was left to bring up three sons more or less on her own. ${ }^{22}$ Both these stories are part of a thread from past to present in Julien's narrative, and each rotates around an unexpected event that resulted in threats to family cohesion and economic survival.

Julien's daughter Lucie also identified a strong link between the female descendants of the family, including the close childhood relationship with her Nan, her mother's mother. She chose for her family object "an octagonal-shaped tin with fruit on it [that] brings back memories of her." ${ }^{23}$ Lucie remarked that her family past, in terms of place of origin, "is quite far removed, but it's still important to me where we've come from. ... There's still that tie to our past and that's nice, parts of it, small parts of it have remained." 24 One of those "small parts" that preserve the family sense of their Danish and Swedish heritage is a children's rhyme, volunteered by both mother and daughter in separate interviews. Lucie sang the following rhyme to the tune of Frère Jacques. Her mother explained that:

there's this little finger rhyme that Mum taught me, that her Mum taught her and I imagine her Mum taught her, and it's probably some form of mangled Danish or Swedish, I'm not sure. But you start off with the thumb:

\section{Tummel Tot \\ Slikkepot \\ Langemand \\ Guldebrand \\ Litte bitte spillemand}

So the tummel tot is your thumb, slikkepot is the finger for slipping into the pot and tasting it, langemand is your longest finger, guldebrand is the finger you wear your gold wedding ring on and litte bitte spillemand is the little bit left over at the end. ${ }^{25}$

Many women interviewees made explicit links between their own lives and those of their female forebears. These stories could draw attention to the enjoyable experiences of family life, including the preservation of specific recipes or the singing of traditional nursery rhymes. Another connection was reflected in the common choice of an inherited domestic utensil as the significant family object, such as a teapot, laundry poker, or iron for baking ginger gems.

But equally many stories were about the difficult lives of female forebears, conveying empathy and admiration for their strength and endurance in the face of endless childbearing, heavy domestic labour and economic hardship. While most of the female participants commented about the positive changes in women's lives over the course of their lifetime, the fear of economic disaster or family breakdown appears to remain. Stories about the vulnerability of mothers and children, revolving around the lives of grandmothers and great-grandmothers, 
continue to be told. Perhaps the emphasis upon "survival" in the past may function as intergenerational cautionary tales conveyed from mothers to daughters, seeking to counterbalance the idealised and powerful cultural myths about marriage and family that often did not, and do not, reflect reality? As the historian John Gillis memorably wrote, "we all have two families, the one that we live with and another we live by. We would like the two to be the same, but they are not. . . . Often fragmented and impermanent, they are much less reliable than the imagined families we live by." 26 "The Missing Link" family stories suggest that the idealised family of cultural imagination often coexists alongside counter-narratives from the family past that are passed down the female generations.

\section{The Interviews}

The structure and focus of the oral history interviews are, of course, also critical to any understanding of both form and content of remembering and oral history. Four experienced oral historians travelled around the country to record the interviews, usually at participants' homes, over a two-year period. ${ }^{27}$ The interviews were designed to be tripartite in structure, and varied in length with the majority between two to three hours. ${ }^{28}$ We began with an open question, "tell us about your own life," recording a relatively short self-directed life history narrative of about half of an hour. This was followed by a longer section, again beginning with an open question along the lines of "what do you know about your family past?" The term "the past" was used deliberately since the word "history" appears to have a very specific and limited meaning in popular consciousness, that of public events and the history of the nation state. We wanted participants, as far as possible, to define for themselves what was significant about their family past and not feel restricted to connections between family and national history, such as the two world wars. This was particularly important given the publicity around World War One commemorations at the time the oral history interviews were being recorded. It was during this section of the interview that participants usually discussed the photographs and/or inherited objects they had chosen in advance for the interview. In the third, much shorter section, we asked a few broad reflective questions around, for example, the family past, present and future, and the interviewee's interest in history and New Zealand history. It was hoped that this tripartite interview structure would facilitate interpretative exploration of the connectionsboth conscious and unconscious - between autobiographical narrative, family stories, and national histories. This analysis, still in progress, will address the role of family memories and stories in Pākehā historical consciousness.

In any oral history interview it is important to consider who the interviewee might be addressing in addition to the oral historian in front of them. This unseen audience sitting behind the interviewer in "The Missing Link" is most likely to have been other family members, as some indeed indicated, and concern about family reputation in the wider community may have been on the interviewees' minds. In these cases, the interviewee might decide not to include specific information, and some aspects of the family past could be either emphasised or omitted. ${ }^{29}$ But it is important to note that family stories can be excluded because they are perceived to be destructive, as the psychiatrist and family therapist John Byng-Hall demonstrated in his account of the "myth of cowardice" passed down through an English family. ${ }^{30}$ A family member who elects not to pass on a memory or story for this reason may be defined as a "buffer generation," protecting the next generation from harm. ${ }^{31}$

For this reason, we asked each participant if there were any memories or stories they had elected not to talk about (without telling us the content). In only a few cases did the interviewee 
confirm that a story had been consciously excluded, while sometimes also voluntarily indicating the broad nature of the exclusion. These primarily related to questions about paternity, "illegitimacy" and birth questions of that nature where the participants were unsure if their understanding or knowledge was widespread among the family. But there were references in many other interviews, sometimes brief but in others more extended, to the birth of children outside wedlock, violence, alcoholism, desertion, or sexual abuse in the past. The conviction that families only aggrandise their family past, expressed at the Canberra conference, therefore appears exaggerated. The participants recounted memories and stories that encompassed family conflict as well as generativity, cruelty as well as kindness, and expressed critique as well as admiration.

But above all the open-ended interview questions enabled participants to shape their own family narratives and emphasise what was important in their understanding of the family past. As a consequence the interviews generated invaluable insights into both past and present. It is precisely this subjective dimension of remembering that is one of the unique strengths of oral history. As Alessandro Portelli pointed out nearly thirty years ago, "the unique and precious element which oral sources force upon the historian and which no other sources possess in equal measure is the speaker's subjectivity." 32 In order to better understand how that subjectivity is expressed in the context of an oral history interview it is essential to consider the nature of remembering.

\section{Remembering}

The tripartite structure of the interviews described above builds upon Jan Assman's mnemonic model revolving around the axis of time, memory, and identity (see Figure 4). ${ }^{33}$

\begin{tabular}{|c|c|c|c|}
\hline Level & Time & Identity & Memory \\
\hline $\begin{array}{l}\text { Individual } \\
\text { (neurological) }\end{array}$ & inner, subjective time & Inner self & $\begin{array}{l}\text { individual memory } \\
\text { recent past }\end{array}$ \\
\hline Social & $\begin{array}{l}\text { Social time } \\
80-100 \text { years } \\
\text { Moving horizon of three to } \\
\text { four interacting generations }\end{array}$ & $\begin{array}{l}\text { Social self, person } \\
\text { as carrier of social } \\
\text { roles }\end{array}$ & $\begin{array}{l}\text { "communicative } \\
\text { memory" } \\
\text { living, embodied } \\
\text { memory; informal, } \\
\text { vernacular language }\end{array}$ \\
\hline Cultural & $\begin{array}{l}\text { historical, } \\
\text { mythical, } \\
\text { cultural time }\end{array}$ & cultural identity & $\begin{array}{l}\text { cultural memory } \\
\text { traditions, symbolic, } \\
\text { ceremonial; } \\
\text { specialised carriers } \\
\text { hierarchically } \\
\text { structured }\end{array}$ \\
\hline
\end{tabular}

Figure 4 
Assman identifies three temporal levels in memory, the individual, social and cultural. However, these three levels of memory are not discrete or necessarily self-reinforcing. Indeed, picking up on Bruner's notion of the importance of the peripeteia in narrative, the argument here is that rather than converge these different mnemonic dimensions often come into conflict, particularly when family behaviour is contrary to social norms or cultural beliefs. The following excerpt from an interview illustrates this point. Rosemary, retired and in her early seventies at the time, recounted an incident that had been passed down from her mother. It concerns Rosemary's sociable Irish grandmother who, in the mid-1920s, lived in a remote part of Taranaki where her husband ran a sawmill:

My mother said, "My mum used to go off and leave us a lot. And Magdalene, the oldest daughter, used to have to do the cooking and everything. And she ran away. ... She had to do all the work, when she was only 15,16 years old.

She was taking care of the other seven kids, and cooking with a wood fireplace.... My poor dad had to come in from the sawmill and there was really nothing to eat ... And it was all Magdalene's fault because she ran away, but then she should have run away because she had to work too hard." So that was one of her stories. . . Y Yes, her mother liked to go off and leave them. ${ }^{34}$

This is a personal memory for Rosemary's mother who remembers the specific incident from her childhood, probably etched into her memory through the emotional turmoil of Magdalene's disappearance and her own failed attempt to cook scones in her older sister's absence. It is also a story passed down from mother to daughter and is part of communicative memory within the family. Finally, the import of this event is drawn out in the coda, the retrospective evaluation regarding the meaning of the story. In this case, the implicit criticism of the sociable grandmother, and the question whether Magdalene was really at fault or not, suggest ambivalence about the social and cultural expectations governing the domestic responsibilities of mothers and daughters.

There is one further dimension of remembering that is particularly relevant to the family memory project, and this concerns the changing focus of memory over the life course. Memories derive, of course, from different periods of our lives, and therefore often reflect the specific focus or preoccupation of our lives at that point. ${ }^{35}$ In the family oral histories recorded for this research, memories from childhood, adolescence, and adulthood clearly reflect different life stage memory development and preoccupations, and these broadly correspond with the psychosocial developmental stages identified by the psychologist and psychoanalyst Erik Erikson. ${ }^{36}$ Memories from childhood revolved primarily around the senses and emotions. ${ }^{37}$ Many of these stories concerned grandparents, sensory memories such as the taste and smell of baking, or expressions of emotional warmth through physical affection. The childhood attachment to affectionate grandparents often carried through, as evident in earlier oral history excerpts, to the choice of inherited objects or the photographs participants selected for the interviews. But others, as in the following excerpts, recalled emotional coldness and the absence of physical affection. One of the unexpected links made in some of these stories about grandparents reflects childhood empathy and identification with farm animals, particularly the horses, and the kind or harsh treatment they received.

Des, a college lecturer and farmer, was born in Christchurch in 1926 of German and Irish migrant forebears who farmed on the Banks Peninsula. Des remembered one grandmother with great warmth, while the other generated quite different memories. Des lived with his Irish Catholic paternal grandmother in 1936 in order to attend school, "and [I] got to know this 
caustic, unlovable woman who'd had a hard life ... and I think of my wife and me with our grandchildren surrounded by love, but when I stayed with her as a young boy I never sat on her knee or any of those touchy-feely things. It was a different experience." 38 On one occasion when he was eight years old, he told his daughter, this grandmother locked him inside the house when he was unwell so that she could go to church. ${ }^{39}$ Des also remembered his German maternal grandfather as a "hard man. . . . I knew him well as a child, but he had no gentleness about him somehow. He was hard on his livestock. . . . I can remember him beating his draft horse, you know, to make it pull harder." ${ }^{40}$ Emotional warmth and kindness, or their opposite, dominate the childhood recollections of grandparents.

Turning to memories from adolescence, these often conveyed a search for beliefs and values as part of a shift in psychological orientation towards the external world. This is particularly clear in adolescent observations of grandparents' behaviour, and the following example is from a family with a deep Christian religious commitment over several generations. An engineer, Peter was born in 1974 and he recalled that his grandfather was born into a very poor family with fourteen children. He had met his wife in Egypt during the Second World War after which he won a veteran's ballot for a farm in the Waikato. Peter's memories of this maternal grandfather revolved around his perception of the Christian values that informed his grandfather's life and admiration for what his grandfather had achieved despite an impoverished and difficult childhood. "My grandfather on that side is someone I've always looked up to a lot for his character," he commented, "partly because of his upbringing but he was also very involved in the community, through the church, and was a self-aware sort of person." 41 The principle of Christian service to others connected all three sections of Peter's interview from his childhood and working life through to his hopes for his two young daughters in the future. Peter was far from unusual in making these kinds of connections between the experiences and values exemplified in a grandparent's life story and the direction of their own.

Finally, we consider adult family memory and in particular the process of transmission. A substantial body of work in cultural and social psychology has focused upon Erikson's concept of generativity, the desire to nurture and guide the next generation. ${ }^{42}$ Family stories about the past are considered to be an important aspect of generativity, and the following oral history interview with Tania, an engineer living in Wellington who was born in 1972, brings together the themes of gender, communicative memory and generativity that are central to this article. It also adds one more theme, that of place. Tania's English forebears migrated to New Zealand in the 1840s. They farmed in various places in Marlborough including the Awatere, Kaituna and Tuamarina Valleys and Pelorus Sound and members of her family continue to live in the region. Growing up in Marlborough she remembered that:

My grandmother was very passionate about family history. ... And so she, right from a young age, she was always telling us little stories about her aunts and uncles and grandparents, so I grew up with it. . . . My grandmother had a great love for the Sounds and we had done multiple boat trips around where we found gravesites, because my grandmother loved history so much, of various ancestors, and she'd explained who'd lived where and how they worked.... She used to take us out in the dinghy and pretend we were ancestors or we were Māori people doing things and we were reenacting parts of history, or we were Captain Cook landing, so she taught us a lot about, we could actually play, but she was teaching us about historic events that had happened. ${ }^{43}$ 
Tania's memories of historical excursions with her grandmother gave her a profound sense of identification with both her family past and the landscape and history of the Marlborough Sounds. The use of a national random sample provided the opportunity to explore the wide range of connections to the New Zealand environment and to assess the significance of place for our participants. Few of our interviewees appear to have received quite such a historically contextualised sense of place as Tania did from her grandmother, but a connection between the family and an urban or rural place, in one way or another, enters most oral histories recorded for this research into family memory.

\section{Conclusions}

Returning to the first of the two questions with which this article began, whether New Zealanders of European descent share oral histories about the family past, the answer is very clearly yes. The information passed down through family memory, however, cannot be understood through precisely the same theoretical lens and set of questions that drive analysis of the written record. Rather, it is essential to approach family memory in the context of what we know about the processes of remembering and draw on the interpretative and conceptual frameworks that have transformed memory studies over recent decades. The temporal frameworks of memory differ from the linear, chronological approach to time most commonly found in historical scholarship, and family stories represent an alternative way of understanding the past. The approach to remembering adopted in this research project recognizes that knowledge about the family past is derived from multiple sources, including personal experience, three-generational communicative memory, and cultural memory embedded in societies and cultures. Of these, communicative memory is vital for the oral transmission of family memories and stories across generations. Beyond great-grandparents, it is rare for anecdotes about an ancestor to achieve the same multidimensional intensity of a memory derived from direct encounter. The depth of family memory is contingent, therefore, upon longevity and generativity of the eldest generation. This composite temporal framework of memory, one historian proposed, could be understood as a "fourth discrete dimension of historical time." 44 The tensions between these different temporal frameworks of memory generate much of the content of family stories, with accounts of expectations and disappointments, successes and failures, relationships and responsibilities driving the narratives.

Family stories also reflected memories embedded over the life course, from the sensory and affective memories of childhood to the combined experiential and moral appraisals of adolescence and adulthood. These were intertwined with selective aspects of genealogical research in many of the interviews, but insights into the interior world of family behaviour in the past, such as an eldest daughter's travails in remote 1920s Taranaki or a small boy being locked in the Christchurch house so that his grandmother could go to church, have been passed orally down the generations. As Jerome Bruner argued, narratives revolve around a peripeteia ranging from the unexpected to a sudden crisis, and consequently the stories provide valuable glimpses into relationships and behaviour in the past, revealing the tensions between expectation and experience in the interior world of the family. For most families, everyday incidents from the past such as these are not written down or preserved in family archives, and yet through communicative memory may exert a significant influence upon contemporary beliefs or hopes. They may also function as valuable intergenerational cautionary tales, a counterweight to the myths of family life that permeate popular culture. 
This article identified a "gender gap" at the heart of the family as a mnemonic community. Many more women than men responded and participated in the research, and they were both particularly interested in their female ancestors and seemed to play a far greater role in the oral transmission of family memory. Here I want to propose two preliminary and related arguments concerning the preponderance of women in the communication of family memory. First of all, most of the women recorded for this project identified changes in women's domestic and economic lives that made their experiences very different from those of their mothers and grandmothers. Despite this, stories about grandmothers' hard domestic labour, responsibility for the care of elderly parents and children, and experience of economic disaster in the case of premature death or abandonment, continue to have powerful traction in family memory. These stories appear to reflect deep-seated fears of family dissolution or of a sudden downward spiral in economic fortunes that continue to be relevant in contemporary women's lives and may influence present-day political behaviour.

Studies in electoral behaviour have long identified a "gender gap," with women more supportive of social service spending. ${ }^{45}$ The 2014 New Zealand Election Study, for example, concluded that "women tend to favour more expenditure than men do on universal benefits such as health, education and New Zealand Superannuation, particularly women between the ages of 40 and 60," with younger women significantly more in favour of higher expenditure on targeted benefits such as unemployment and welfare. ${ }^{46}$ This gender gap is not unique to New Zealand, and one political scientist recently concluded that there is "little on offer to clarify the circumstances that contribute to the strength of this relationship." ${ }^{47}$ On the contrary, the American psychologist Carol Tavris made the argument twenty years ago that "the gender gap is largely an experience gap. More women than men today worry that they or their children might need a safety net if they lose a job, lose a partner or lose their health. More women than men are taking care of aging, infirm parents. Many more single mothers than single fathers are raising children on their own." ${ }^{48}$ This is surely one reason why the stories about the difficult and sometimes wretched lives of female forebears in New Zealand continue to have traction in the present. Their daughters, granddaughters and great-granddaughters continue to bear, in most cases, primary responsibility within the family for the unpaid care of the young and the old and they are aware of both their own and their family members' vulnerability to economic or other misfortune. In other words, while aspects of women's lives have certainly changed from those of their female forebears, the continuities in family roles and responsibilities largely remain, as does the purchase of these family stories about the past.

The second argument builds upon the first. Returning to Bruner's conclusions regarding the narrative construction of self-identity, the family stories recorded for "The Missing Link" suggest that a similar narrative process is in progress within the family. Women who, in most cases, continue to take primary responsibility for the care of children and family relationships in New Zealand, are also central to the process of creating "the family" as a narrative entity. Family members are bequeathed, to a lesser or greater extent, a narrative inheritance that anchors the family in time, place, and moral universe. The female narrative inheritance is complex and includes both positive and adverse stories. The latter, revolving around Bruner's peripeteia, tell of a family environment that is uncertain; expectations may be unfulfilled, relationships fail or disaster strike, sometimes with damaging emotional, social or economic consequences reverberating down the generations. These stories fit within the thematic categories of meaning making and agency in narrative, with a particular emphasis upon responsibility. In terms of agency, descendants remember how great-grandmothers and grandmothers fulfilled their responsibilities to their children in extremely difficult 
circumstances, seeking to ensure the survival of the family. This "responsibility narrative" also has parallel meaning making functions. It is comprised of cautionary tales for daughters and granddaughters, reminding them of the potential instability of the families that, to recall Gillis's phrase, "we live with." In these ways, women's experiences and agency in the past, as daughters, mothers and grandmothers, form a unifying thread in their female descendants' family narratives.

Family memories and stories therefore matter for both past and present. In terms of the past, these can provide valuable insights into family relationships and the interior world of the family, contributing to a richer, deeper historical knowledge about such a fundamental social dimension of human cultures. In terms of the present we need to better understand how remembering within the family, for both men and women, is integrated into narrative identities, influencing both present-day cultural and political behaviour as well as future plans and prospects.

Acknowledgements: I wish to acknowledge and express my gratitude to Jack Vowles for advice and assistance with the implementation of the random sample, and Jared Commerer for indexing the interviews and compiling Table 1 and Figures 1-3. I would also like to thank both peer reviewers for their comments and suggestions.

"The Missing Link" research project was funded by the Marsden Fund Te Pūtea Rangahua a Marsden, New Zealand. The research received ethics approval 22947 from the Victoria University of Wellington Human Ethics Committee, 13 May 2016.

\footnotetext{
${ }^{1}$ Tanya Evans, "Secrets and Lies: The Radical Potential of Family History," History Workshop Journal 71, no. 1 (Spring 2011): 49-73.

${ }^{2}$ See "Historical census forms are a valuable information source for family (and other) historians", http://archive.stats.govt.nz/Census/2013-census/info-about-the-census/intro-to-nz-census/history/didyou-know/historic-forms.aspx

${ }^{3}$ Rāwiri Taonui, "Whakapapa-Genealogy," Te Ara, The Encyclopedia of New Zealand, https://teara.govt.nz/en/whakapapa-genealogy; Ann Salmond, "Back to the Future: First Encounters in Te Tai Rawhiti," Journal of the Royal Society of New Zealand 42, no. 2 (2012): 69-77; Daniel Hikuroa, "Mātauranga Māori-the Ūkaipō of Knowledge in New Zealand," Journal of the Royal Society of New Zealand 47, no. 1 (2017): 5-10; Nepia Mahuika, Rethinking Oral History and Tradition: An Indigenous Perspective (Oxford: Oxford University Press, forthcoming 2019). ${ }^{4}$ Astrid Erll, "Locating Family in Cultural Memory Studies," Journal of Comparative Family Studies 42, no. 3 (2011): 303-18. For specific examples see Kate Darian-Smith and Paula Hamilton, eds., Remembering Migration (Basingstoke: Palgrave Macmillan, 2019); Jennifer R. Nájera, "Remembering Migrant Life: Family Collective Memory and Critical Consciousness in the MidCentury Migrant Stream," Oral History Review 45, no. 2 (2018): 211-31; Andor Skotnes, ed., Migration and Identity (New York: Routledge, 2005); Janet Jacobs, The Holocaust Across Generations: Trauma and its Inheritance among Descendants of Survivors (New York: NYU Press, 2017); and Orlando Figes, "Private Life in Stalin's Russia: Family Narratives, Memory and Oral History," History Workshop Journal 65, no. 1 (2008): 117-37.

${ }^{5}$ Jerome Bruner, "Life as Narrative," Social Research 71, no. 3 (Fall 2004): 691-93, 708.
} 
${ }^{6}$ Jerome Bruner, Making Stories: Law, Literature, Life (New York: Farrar, Straus and Giroux, 2002), 15.

${ }^{7} 1914$ has been defined in different historiographical contexts as the end of the "long nineteenth century"; in this research context the end date of 1914 also ensured an oral history cohort with three to six generations in New Zealand.

${ }^{8}$ Carla Pascoe Leahy, "Selection and Sampling Methodologies in Oral Histories of Mothering, Parenting and Family," Oral History 47, no. 1 (Spring 2019): 105-06.

${ }^{9}$ Katie Holmes, Alistair Thomson, Kate Darian-Smith, and Penelope Edmonds, "Oral History and Australian Generations," Australian Historical Studies 47, no. 1 (2016): 2.

${ }^{10}$ Holmes et al., "Oral History and Australian Generations," 3.

${ }^{11}$ Leahy, "Selection and Sampling," 107.

${ }^{12}$ Anna Green, "Intergenerational Family Stories: Private, Parochial, Pathological?" Journal of Family History 38, no. 4 (2013): 387-402.

${ }^{13}$ Statistics New Zealand: https://www.stats.govt.nz/infographics/new-zealand-as-a-village-of-100people and https://www.stats.govt.nz/infographics/new-zealand-as-a-village-of-100-people-2018-censusdata.

${ }^{14}$ See Anna Green and Kayleigh Luscombe, "Family Memory, 'Things,' and Counterfactual Thinking," Memory Studies, first published 23 June 2017, https://doi.org/10.1177/1750698017714837

${ }^{15}$ Leahy, "Selection and Sampling," 105-16; Holmes et al., "Oral History and Australian Generations," 1-7.

${ }^{16}$ Statistics New Zealand, Women at Work: 1991-2013 (Wellington, 2015), 11.

${ }^{17}$ Ed de St Aubin, Dan P. McAdams, and T'ae-Ch'ang Kim, eds., The Generative Society: Caring for Future Generations (Washington: American Psychological Association, 2004), 19.

${ }^{18}$ Robyn Fivush and Kelly Marin, "Development of a Gendered Narrative Identity," in APA

Handbook of the Psychology of Women: History, Theory, and Battlegrounds, ed. C. B. Travis, et al. (Washington: D.C. American Psychological Association, 2018), 473-87; Robyn Fivush and Natalie Merrill, “An Ecological Systems Approach to Family Narratives," Memory Studies 9, no. 3 (2016): 305-14; Robyn Fivush, "Remembering and Reminiscing: How Individual Lives are Constructed in Family Narratives," Memory Studies 1, no. 1 (2008): 49-58; Elaine Reese, Catherine A. Haden, and Robyn Fivush, "Mother-Child Conversations about the Past: Relationships of Style and Memory over Time," Cognitive Development 8, no. 4 (1993): 403-40.

${ }^{19}$ Roy Rosenzweig and David Thelen, The Presence of the Past (New York: Columbia University Press, 1998), 30.

${ }^{20}$ FMP02_1O, Wellington, 3 September 2016: T3:00.01.11; T3:00.47.39. Recordings are currently held by the author, and with permission of the interviewee will be deposited in the Alexander Turnbull Library Oral History Collection, Wellington.

${ }^{21}$ FMP02_1O: T3:00.21.48.

${ }^{22}$ FMP02_1O: T3:00.26.24.

${ }^{23}$ FMP02_2O, Wellington, 25 February 2017: T3:00.00.24.

${ }^{24}$ FMP02_2O: T3:00.03.45.

${ }^{25}$ FMP02_1O: T4:00.00.23; FMP02_2O, Wellington, 25 February 2017: T3:00.13.10. The rhyme is not written exactly as it sounded phonetically in the audio recording.

${ }^{26}$ See John R. Gillis, A World of Their Own Making: Myth, Ritual, and the Quest for Family Values (Cambridge, Mass.: Harvard University Press, 1996), xv.

${ }^{27}$ The interviewers were Anna Green, Megan Hutching, Pip Oldham, and Helen Frizzell.

${ }^{28}$ Note that the interviews generally lasted longer than the recording, in that the preliminary oral introductions and explanations, and the lengthy process of completing the three agreement forms were not recorded. A separate article reflecting on the process of interviewing for this research project is in progress and will be published in the journal Oral History in New Zealand.

${ }^{29}$ Ashley Barnwell, "Hidden Heirlooms: Keeping Family Secrets across Generations," Journal of Sociology 54, no. 3 (2018): 446-60; Annette Kuhn, Family Secrets: Acts of Memory and Imagination (London: Verso, 1995).

Journal of New Zealand Studies NS29 (2019), 3-19 https://doi.org/10.26686/jnzs.v0iNS29.6257 
${ }^{30}$ John Byng-Hall, "The Power of Family Myths," in The Myths We Live By, ed. Raphael Samuel and Paul Thompson (London: Routledge, 1990), 216-24.

${ }^{31}$ See John Kotre and Kathy B. Kotre, "Intergenerational Buffers: 'The Damage Stops Here,"” in Generativity and Adult Development, ed. Dan P. McAdams and Ed de St Aubin (Washington, D.C.: American Psychological Association, 1998), 367-89.

${ }^{32}$ Alessandro Portelli, The Death of Luigi Trastulli and Other Stories: Form and Meaning in Oral History (Albany: State University of New York Press, 1991), 50.

${ }^{33}$ Jan Assman, "Communicative and Cultural Memory," in Cultural Memory Studies: An International Interdisciplinary Handbook, ed. Astrid Erll and Ansgar Nünning (Berlin, New York: Walter de Gruyter, 2008), 109. This version of Assman's table includes additional information provided in the text of his chapter.

${ }^{34}$ FMP 36_2G, Whakatane, 3 October 2017: T1:01.43.00.

${ }^{35}$ See Michael W. Pratt and Barbara H. Fiese, eds., Family Stories and the Life Course across Time and Generations (Mahwah, N.J.: Lawrence Erlbaum, 2004), and Jodi A. Quas and Robyn Fivush, eds., Emotion and Memory in Development: Biological, Cognitive, and Social Considerations (Oxford: Oxford University Press, 2009).

${ }^{36}$ Erik Erikson, Identity and the Life Cycle (New York: W.W. Norton [1959] 1994); Erik Erikson, Youth: Change and Challenge (New York: Basic Books, 1963).

${ }^{37}$ Paula Hamilton, "The Proust Effect: Oral History and the Senses," in The Oxford Handbook of Oral History, ed. Don Ritchie (Oxford: Oxford University Press, 2012), 221; Constance Classen, Worlds of Sense: Exploring the Senses in History and Across Cultures (New York: Routledge, 1993), 6.

${ }^{38}$ FMP_03_1O, Akaroa, 9 September 2016: T2:00:36.07.

${ }^{39}$ FMP_03_2G, Darfield, 20 October 2016: T1:01.43.22.

${ }^{40}$ FMP_03_1O, Akaroa, 9 September 2016: T2:00.53.00.

${ }^{41}$ FMP_21_2G, Christchurch, 18 October 2016: 00.33.24.

${ }^{42}$ Dan P. McAdams, Holly M. Hart, and Shadd Maruna, "The Anatomy of Generativity," in Generativity and Adult Development, ed. McAdams and de St. Aubin, 7-43; see also de St. Aubin, McAdams, and Kim, eds., The Generative Society.

${ }^{43}$ FMP_11_3O, Wellington, 23 February 2017: T2:00.19.10.

${ }^{44}$ Bill Schwarz, "“Already the Past': Memory and Historical Time," in Memory Cultures: Memory, Subjectivity and Recognition, ed. Susannah Radstone and Katharine Hodgkin (New Brunswick: Transaction Publishers, 2007), 139.

${ }^{45}$ Jack Vowles, Hilde Coffé, and Jennifer Curtin, "The Gender Dimension of Inequality," in A Bark But No Bite: Inequality and the 2014 New Zealand General Election (Canberra: ANU Press, 2017), 190. http://www.jstor.org/stable/j.ctt1vw0p68.15 ${ }^{46}$ Vowles, Coffè, and Curtin, "The Gender Dimension," 212.

${ }^{47}$ Laurenz Ennser-Jedenastik, "Campaigning on the Welfare State: The Impact of Gender and Gender Diversity," Journal of European Social Policy 27, no. 3 (2017): 215.

${ }^{48}$ Carol Tavris, "Misreading the Gender Gap," New York Times, 17 September 1996, https://www.nytimes.com/1996/09/17/opinion/misreading-the-gender-gap.html; Kristi Andersen, "The Gender Gap and Experiences with the Welfare State," PS: Political Science and Politics 32, no. 1 (1999): 17. 